\title{
Principles-Based Accounting Standards, Earnings Management and Price Efficiency
}

\author{
Michael Ehud Yampuler ${ }^{1}$ \\ ${ }^{1}$ University of Houston, USA \\ Correspondence: Michael Ehud Yampuler, University of Houston, USA
}

Received: January 31, 2019

Accepted: April 9, 2019

Online Published: April 15, 2019

doi:10.5430/afr.v8n2p171

URL: https://doi.org/10.5430/afr.v8n2p171

\begin{abstract}
The issue of principles-based accounting standards has been attracting growing interest since the emergence of the International Financial Reporting Standards (IFRS) as a global phenomenon, and the United States consideration of IFRS adoption. This paper studies the effect of a move towards principles-based accounting standards on price efficiency in the equity market. I assume a move towards principles-based standards requires the firm's manager to use more of his private, though more subjective, information for financial reporting. I model the manager's reporting decision as a trade-off between increased compensation through earnings management and a cost associated with earnings management (such as litigation, SEC enforcement, and manipulation effort). I find that the effect of a move towards principles-based accounting standards on price efficiency is non-monotonic. When standards are highly rules-based, reducing the use of rules-based standards increases price efficiency. However, at some point, this relation reverses. The optimal mix of rules and principles reflects a trade-off between two types of effects on price efficiency: predictive ability and comparability. In addition, expected earnings management is non-monotonic in the use of rules-based standards. Finally, I find that rules intensity and managerial compensation incentives act as complements, such that higher managerial compensation incentives require more rules-based standards for price efficiency to be maximized.
\end{abstract}

Keywords: principles-based standards, rules-based standards, IFRS adoption, earnings management, price efficiency

\section{Introduction}

The issue of principles-based accounting standards has been attracting growing interest since the emergence of the International Financial Reporting Standards (IFRS) as a global phenomenon. While IFRS is generally viewed as a principles-based system, US GAAP has been often criticized for being too rules-based. This resulted in the Sarbanes-Oxley Act requiring the U.S. Securities and Exchange Commission (SEC) to study the adoption of a principles-based accounting system. Although the SEC released a comprehensive report in 2012 stating that there is no vast support for replacing U.S. GAAP with IFRS, the report did recommend the incorporation of IFRS, with its principles-based approach, into the U.S. financial system by continued convergence or by other means. The implementation of this recommendation was evidenced by the recent adoption of a new revenue recognition standard (ASC 606, effective 2018) and a new lease accounting standard (ASC 842, effective 2019) which are both significantly more principle-based relative to the old standards they superseded.

Given the lack of any authoritative definition of principles-based standards, there is some disagreement whether U.S. standards are in fact more rules-based or principles-based. Some argue that U.S. accounting standards are generally principles-based because they are written to apply the FASB's underlying conceptual framework (Schipper, 2003). However, others point to U.S. GAAP's many scope and treatment exceptions, detailed implementation guidance, clarifications, specific criteria, and "bright-line" thresholds as evidence of a heavy reliance on "rules-based" standards.

As the nature of standards affect the way the readers of the financial statements interpret financial information, investigating the effect of standards on price efficiency is of significant interest. A principles-based system may be considered desirable because it requires managers to exercise professional judgment in financial reporting, improving investors' ability to interpret the underlying economic reality associated with each company, and thereby increasing price efficiency. A rules-based standard system may be seen as undesirable because it allows highly incentivized managers to engage in financial and accounting engineering to structure transactions "around" the rules, 
subverting high-quality financial reporting, and dampening price efficiency. However, some evidence shows that earnings management is increased when standards are less rules-based (Agoglia et al. 2011; Nelson et al. 2003), possibly reducing the above-mentioned benefits of the principles-based approach. Hence, the effect of a move towards principles-based standards on price efficiency is unclear.

In this paper I abstract from the specifics of IFRS and U.S. GAAP and study, using analytical tools, the effects of a move towards principles-based accounting standards on price efficiency in the equity market. In addition, I investigate how the relation between standards and price efficiency is influenced by managerial compensation incentives.

As rules-based standards are considered to limit the extent to which managers need to apply professional judgment in reporting, I assume a move towards accounting principles requires the firm's manager to use more of his private, though more subjective, information in financial reporting. I assume the manager has some discretion to manage earnings, either by structuring transactions to circumvent rules, or by manipulating accruals. When engaging in earnings management, the manager faces disutility from effort spent on transactions structuring and accrual manipulation, risk of future litigation, SEC enforcement, conflict with auditors, psychic costs, and loss of reputation. More rules-based standards decrease the difficulty of transaction structuring but increase the difficulty of accrual manipulation. I assume the total effect of moving towards principles-based standards on the manager's average disutility may be negative or positive, and that the variance in disutility across managers increases. I make this assumption about the variance to capture the notion that as standards become more principles-based, the consequences of earnings management become more uncertain for managers. The equilibrium analysis is framed in a rational-expectations setting so that the manager rationally anticipates the effect of reported earnings on the stock price.

I find that the effect of a move towards principles-based accounting standards on price efficiency is non-monotonic. When standards are highly rules-based, reducing the use of rules increases price efficiency. However, at some point, this effect reverses so that relying too much on principles-based standards decreases price efficiency. The optimal mix of rules and principles reflects a trade-off between two types of effects that affect price efficiency: predictive ability and comparability. The more standards are principles-based, the more management's private information is reflected in financial statements, giving the numbers more predictive ability regarding the firm's value. However, if standards are more rules-based, the market has less uncertainty regarding the manager's possible earnings management motivation (or disutility), increasing comparability between firms' reports.

I also show that expected earnings management in financial statements is non-monotonic in the intensity of the use of rules in standards. In some situations, making standards less rules-based decreases expected earnings management, even though managers are permitted more room for judgment. However, this only occurs when current standards are already primarily principles-based. When the current accounting approach is mostly rules-based, making standards less rules-based generally increases expected earnings management.

About the role of managerial compensation incentives, I find that accounting rules and managerial compensation incentives act as complements, meaning that more rules-based standards require higher managerial compensation incentives for price efficiency to be maximized.

\section{Literature Review}

A few papers have discussed the effect of rules-based versus principles-based standards on earnings quality and earnings management, in all its forms. Beck, Behn, Lionzo, \& Rossignoli (2017) found that a move toward a more principles-based definition of control, both in IFRS and US GAAP, did not have a significant effect on the extent of transaction-structuring (a form of earnings management) connected to the presentation of equity method investments. Collins, Pasewark, \& Riley (2012) compared companies that use US GAAP's "bright lines"/rules-based lease standard to companies that use the more principles-based IFRS lease standard and found that the US GAAP companies are more likely to report operating off-balance-sheet leases. This may indicate that US GAAP companies are engaging in more earnings management (either by using aggressive accounting or by transaction structuring). Agoglia, Doupnik, \& Tsakumis (2011), using an experiment, found that managers engage in less aggressive reporting when standards are less precise (more principle-based). Cussatt, Huang, \& Pollard (2018), using a German sample of firms that had to switch from US GAAP (considered more rules-based) to IFRS (considered more principles-based), have found that those companies increased their earnings quality, using a few alternative earnings quality proxies (earnings smoothing activities, value relevance, and conditional conservatism). Sun, Cahan, \& Emanuel (2011), using a sample of foreign companies cross-listed in the US that have adopted IFRS, found no evidence of improved earnings quality due to the adoption when using a few proxies (absolute discretionary accruals, 
timely loss recognition, or a long-window ERC) but did find improvement in earnings quality when using other proxies (incidence of small positive earnings and earnings persistence). Jamal and Tan (2010) find in an experiment using experienced financial managers that a more principles-based standard system improves financial reporting quality, but only in cases where auditors are in a more principles-based mindset. Guo and Luo (2017) show that in countries with strong contract enforcement, companies tend to have higher exports, and the exports go to more destinations.

As to effect of principles-based standards on auditors (which indirectly affect the audited companies and the value of the audited information), Peytcheva, Wright, \& Majoor (2014) find that when standards are more principle based, auditors assume more accountability for their opinions, which will result in more requests for evidence from their clients. Gimbar, Hansen, \& Ozlanski (2016) present experimental evidence that jurors will place more liability on auditors when standards are less precise (more principle-based). However, Kadous and Mercer (2016) show that less precise standards will cause jurors to less second-guess auditors' opinions. In addition, Kadous and Mercer (2012) show that jurors will provide less verdicts to auditors when standards are more principles-based.

As to the effect of principles-based standards on the costs of earnings management, Donelson, McInnis, \& Mergenthaler (2012) find that companies that use a more rules-based lease standard (ASC 840 in US GAAP) classify more leases as operating leases than companies that use a more principles-based lease standard (like IAS 17 in IFRS). As operating leases are considered a more attractive reporting option for most companies, this finding seems to indicate that companies engage in more earnings management when standards are more rules-based. Boone, Linthicum, \& Poe (2013) find that the U.S. SEC commented (challenged) financial reports that were based on more rules-based standards. This seems to indicate that principles-based standards may reduce the cost of earnings management for companies.

All the above papers, which use archival or experimental methodologies, compare a certain level of rules (like in U.S. GAAP) to a certain level of principles (like in IFRS). My paper contribution is that by employing an analytical approach I can study a continuum of rules' intensity levels and find whether the effect on earnings quality and earnings management is monotonic for all possible rules' intensity levels. In addition, as a robustness test, I endogenize management compensation in the presence of principles-based standards, a topic that was not investigated in the literature previously.

\section{The Model}

Consider a firm's manager and a perfectly competitive equity market with risk neutral investors in a one-period game. The firm has terminal value of $v$. Neither the manager nor the market observes $v$. The manager's and the market's priors for $v$ are normally distributed with mean $\mu_{v}$ and variance $\sigma_{v}^{2}$.

The firm's manager privately observes a signal $x$ as a measure for the firm's terminal value. This signal is not perfect in the sense that it does not reveal the value precisely:

$$
x=v+\varepsilon_{x}
$$

where the noise factor $\varepsilon_{x}$ has normal distribution with mean zero and variance $\sigma_{x}^{2}$.

Rules-based standards, which require high verifiability, are limited in the sense that they are less capable of capturing the complexity of the firm's economic performance. The less extensive the use of rules-based standards (i.e., standards are more principles-based), the more standards require the firm's management to use its private, though more subjective, information on $x$, for financial reporting. Consequently, the report required by a standard reflects more of what the management privately knows about the real value of the firm the more the standards are principles-based.

For example, an accounting principle can require a firm to record a capital lease whenever the risks and benefits of ownership have been transferred from the lessor to the lessee, while a rule can require the firm to record a capital lease only when the sum of the undiscounted lease payment is above 90 percent of the fair value of the leased item. Before considering any kind of earnings management, the report required by the principle will reflect more accurately the manager's private information, while the report required by the rule will be "noisier."

I assume that the manager is required by a given set of accounting standards to report a value of $y(x, \alpha)$, where $\alpha$ is a measure of the extent to which the standards are rules-based (use of rules). I assume $y(x, \alpha)$ is normally distributed with the moments of $y(x, \alpha)$ as follows: 


$$
\begin{gathered}
E[y(x, \alpha)]=x \\
\sigma[y(x, \alpha) \mid x]=\alpha \sigma_{y}
\end{gathered}
$$

This structure captures the notion that standards that are more rules-based (high $\alpha$ ) are noisier in reflecting a manager's private information (even if they are unbiased, as I have assumed). However, it is important to note that $y(x, \alpha)$ is only the required report by the standards, and it does not include any earnings management that the manager engages in.

After privately observing $x$ and $y(x, \alpha)$, the manager provides a public accounting report, $r$, and the market price is determined. Therefore, the market price is a function of the investor's prior beliefs and the accounting report. Perfect competition and risk neutrality of the equity market drive the price to the rational expectation of terminal value, $v$, conditioned upon the accounting report, $r$ :

$$
P=E[v \mid r]
$$

I assume the manager has some discretion to perform earnings management, either by structuring transactions to circumvent rules, or by manipulating accruals. The total sum of earnings management, $b$, is the difference between the required report and the actual reported number. Therefore, the report $r$ will be equal to:

$$
r=y(x, \alpha)+b
$$

when $b$ could be positive or negative.

The manager chooses the level of earnings management to maximize his objective function. I assume the manager's objective function has two elements: managerial compensation incentives and earnings management disutility. Managerial compensation incentives are the manager's incentive package, which usually depends on stock performance. The earnings management disutility reflects a few of the individual manager's properties. First, it can reflect the propensity of the manager to manage earnings (which also can be framed as psychic costs the manager incurs when managing earnings). Second, this coefficient can reflect the perceived risk of future litigation, interaction with the SEC (both enforcement and routine), conflict with auditors, internal conflict with employees, and loss of reputation. Third, it can also reflect individual financial skills needed to manage earnings (affecting the effort needed to manipulate accruals or structure transactions).

Therefore, I model the manger's objective function as:

$$
z P-\frac{1}{\delta} \cdot \frac{b^{2}}{2}
$$

where $z$ is the share of the firm's value which is given to the manager as an incentive. To simplify the analysis, I assume that $z$ is known to the market (this assumption is relaxed in Section 5). The expression $1 / \delta$ is the manager's earnings management disutility coefficient, reflecting all the factors discussed above that affect this disutility.

I assume that the value of $\delta$ is the manager's private information, and that $\delta$ is a normally distributed random variable whose distribution is common knowledge. First, about the variance of this distribution, as earnings management disutility relies on the manager's individual perceptions and his talent for finding ways to manage earnings, we would expect idiosyncrasies to create variation across managers. However, a crucial assumption in my model is that when standards are more principles-based, and managers are required to use more of their own professional judgment in reporting, the effect of those idiosyncrasies is intensified, as the consequences of earnings management (either accrual manipulation or transaction structuring) become more uncertain for managers. In addition, variation in managerial financial expertise is also assumed to have more effect on the required earnings management effort when there are more options for reporting than when the options are limited.

About the effect of standards on the expected value of $\delta$, two opposite influences are to be considered. More rules-based standards may reduce the difficulty of transaction structuring, as it is easier to circumvent a rule when it is narrowly defined. However, more rules-based standards increase the difficulty of accrual manipulation, as there is less room for discretion. Therefore, the total effect of more rules-based standards (a higher $\alpha$ ) on the expected value of $\delta$ may be negative or positive.

Hence, I assume the distribution of $\delta$ has the following moments:

$$
\begin{aligned}
& \sigma(\delta)=(1-\alpha) \sigma_{\delta} \\
& E(\delta)=\mu_{\delta}(\alpha)
\end{aligned}
$$


As was discussed, the variance of $\delta$ decreases with $\alpha$ and the expected value changes with $\alpha\left(\mu_{\delta}^{\prime}(\alpha)\right.$ may be positive or negative).

An equilibrium to the game described above consists of a strategy for the manager, which is the earnings management function $b(x, y, \delta)$, and a pricing function for the market, $P(r)$, which satisfy the following three conditions:

1) $b(x, y, \delta)$ must solve the manager's optimization problem (given his conjecture on the market-pricing function):

$$
b(x, y, \delta)=\operatorname{argmax}_{b} z \hat{P}(r=y(x, \alpha)+b)-\frac{1}{\delta} \cdot \frac{b^{2}}{2}
$$

where $\widehat{P}$ is the manager's conjecture about the market-pricing function.

2) Market price must equal expected firm terminal value, $v$, conditional on a report, $r$, and a conjecture of the market on the earnings management function:

$$
P(r)=E[v \mid r ; \hat{b}(x, y, \delta)]
$$

where $\hat{b}(x, y, \delta)$ is the market's conjecture about the earnings management function.

3) Expectations should be rational, that is:

$$
\hat{b}(x, y, \delta)=b(x, y, \delta)
$$

for all $\{x, y, \delta\}$ and

$$
\hat{P}(r)=P(r)
$$

for all $r$.

I restrict the analysis to linear equilibria, such that price is linear in $r$, and earnings management is linear in $y$ and $\delta$. This is done to simplify the characterization and analysis, while still providing persuasive intuition. Therefore, I assume the equilibrium is of the form:

$$
\begin{gathered}
b(x, y, \delta)=\lambda_{y} y(x, \alpha)+\lambda_{\delta} \delta+\eta \\
\mathrm{P}(\mathrm{r})=\beta \mathrm{r}+\gamma
\end{gathered}
$$

The manager knows that the market forms its price as in equation (11), and that investors believe that the manager forms his earnings management function as in equation (10). Thus, the manager's conjecture regarding the market pricing function is:

$$
P=\hat{\beta} r+\hat{\gamma}=\hat{\beta} y(x, \alpha)+\hat{\beta} b+\hat{\gamma}
$$

Therefore, the manager's objective function is:

$$
z(\hat{\beta} y(x, \alpha)+\hat{\beta} b+\hat{\gamma})-\frac{1}{\delta} \cdot \frac{b^{2}}{2}
$$

and it is strictly concave in $b$. Solving the first order conditions yields:

$$
b(x, y, \delta)=z \hat{\beta} \delta
$$

Equation (13) fits the linear conjecture form $b(x, y, \delta)=\lambda_{y} y(x, \alpha)+\lambda_{\delta} \delta+\eta$, where:

$$
\lambda_{y}=0, \quad \lambda_{\delta}=z \hat{\beta}, \eta=0
$$

and consequently, the report is:

$$
r=y(x, \alpha)+b=y(x, \alpha)+\lambda_{\delta} \delta
$$

Since the investors know that $\lambda_{y}=0$ and $\eta=0$ in the manager's optimal solution for any $\{x, y, \delta\}$, it restricts both to be 0 in its pricing decision.

On the side of the market, using equation (15), and replacing the real $\lambda_{\delta}$ with its conjecture, the expectation in the market price function is calculated as:

$$
P=E[v \mid r]=\mu_{v}+\left[r-\hat{\lambda}_{\delta} \mu_{\delta}-\mu_{v}\right] \cdot \frac{\sigma_{v}^{2}}{\sigma_{v}^{2}+\sigma_{x}^{2}+\alpha^{2} \sigma_{y}^{2}+\hat{\lambda}_{\delta}^{2}(1-\alpha)^{2} \sigma_{\delta}^{2}}
$$

Equation (16) also fits the conjectured linear form: $\mathrm{P}(\mathrm{r})=\beta \mathrm{r}+\gamma$ where:

$$
\beta=\frac{\sigma_{v}^{2}}{\sigma_{v}^{2}+\sigma_{x}^{2}+\alpha^{2} \sigma_{y}^{2}+\hat{\lambda}_{\delta}^{2}(1-\alpha)^{2} \sigma_{\delta}^{2}}
$$




$$
\gamma=(1-\beta) \mu_{v}-\hat{\lambda}_{\delta} \mu_{\delta} \beta
$$

Using the requirement of rational expectation, I replace the conjectures for $\lambda_{\delta}, \beta$ and $\gamma$ with the equilibrium values. Taking the solution for $\lambda_{\delta}$ from equation (14), substituting it for $\lambda_{\delta}$ in equation (17) gives:

$$
\beta=\frac{\sigma_{v}^{2}}{\sigma_{v}^{2}+\sigma_{x}^{2}+\alpha^{2} \sigma_{y}^{2}+z^{2}(1-\alpha)^{2} \sigma_{\delta}^{2} \beta^{2}}
$$

or after rearranging the terms:

$$
\beta^{3} z^{2}(1-\alpha)^{2} \sigma_{\delta}^{2}+\beta\left[\sigma_{v}^{2}+\sigma_{x}^{2}+\alpha^{2} \sigma_{y}^{2}\right]-\sigma_{v}^{2}=0
$$

There exists a unique positive solution, as the left-hand side is negative when $\beta=0$, is monotonically increasing in $\beta$, and approaches positive infinity as $\beta$ approaches positive infinity.

We can also see that $\beta$ is not affected by $\mu_{\delta}$, the expected value of $\delta$, but only by the variance, $\sigma_{\delta}^{2}$. This is because investors back-out the expected value of earnings management from the price (through the intercept of the pricing function). Therefore, the specific assumption made for $\mu_{\delta}$ (increasing or decreasing with $\alpha$ ) does not affect the price efficiency, but just the magnitude of earnings management.

\section{Analysis}

The linear equilibrium in the previous section fits into a regression framework that studies the association between price and earnings. Specifically, the expression for firm value in equation (16) be resulting from a regression of terminal value on reported earnings, where $\beta$ is the predicted association of accounting earnings with equity market values, commonly used in the value-relevance literature (Barth, Beaver, \& Landsman, 2001).

I show that the coefficient $\beta$ is affected by the extent of the use of rules-based standards, $\alpha$, in a non-monotonic way in the following proposition:

Proposition 1: There exists an interior solution between 0 and 1 for rules intensity $\alpha$ that maximizes the price response coefficient $\beta$.

Proof: Calculating the derivative of $\beta$ with respect to $\alpha$, using the implicit function for $\beta$ in equation (20), it is found that:

$$
\frac{\partial \beta}{\partial \alpha}=\frac{2 \beta\left[(1-\alpha) \beta^{2} z^{2} \sigma_{\delta}^{2}-\alpha \sigma_{y}^{2}\right]}{3 \beta^{2} z^{2}(1-\alpha)^{2} \sigma_{\delta}^{2}+\sigma_{v}^{2}+\sigma_{x}^{2}+\alpha^{2} \sigma_{y}^{2}}
$$

The denominator in the right-hand-side of equation (21) is always positive, and so the sign of the derivative is determined by the expression in brackets in the numerator:

$$
(1-\alpha) \beta^{2} z^{2} \sigma_{\delta}^{2}-\alpha \sigma_{y}^{2}
$$

It is easy to see that this expression is negative as $\alpha$ approaches one, and positive as $\alpha$ approaches zero (noting the fact that $\beta$ is bounded between 0 and 1.) That means that $\beta$ reaches a maximum in an interior value of $\alpha$ (between 0 and 1).

An intuitive explanation for this result is that there is a trade-off between two effects: predictive ability and comparability. The limited predictive ability of the rules-based standards system to capture the real economic essence of the business, reflected in $\sigma_{y}^{2}$, becomes more dominant (thus decreasing $\beta$ ) when $\alpha$ approaches 1 . However, the variance in the manager's earnings management disutility (reflected in $\sigma_{\delta}^{2}$ ), which contributes to reduced comparability between firms, becomes more dominant when $\alpha$ approaches zero. Schipper (2003) also notes the possibility of this trade-off when principles-based standards are considered. Figure 1 shows $\beta$ as a function of $\alpha$, using a numerical example. 


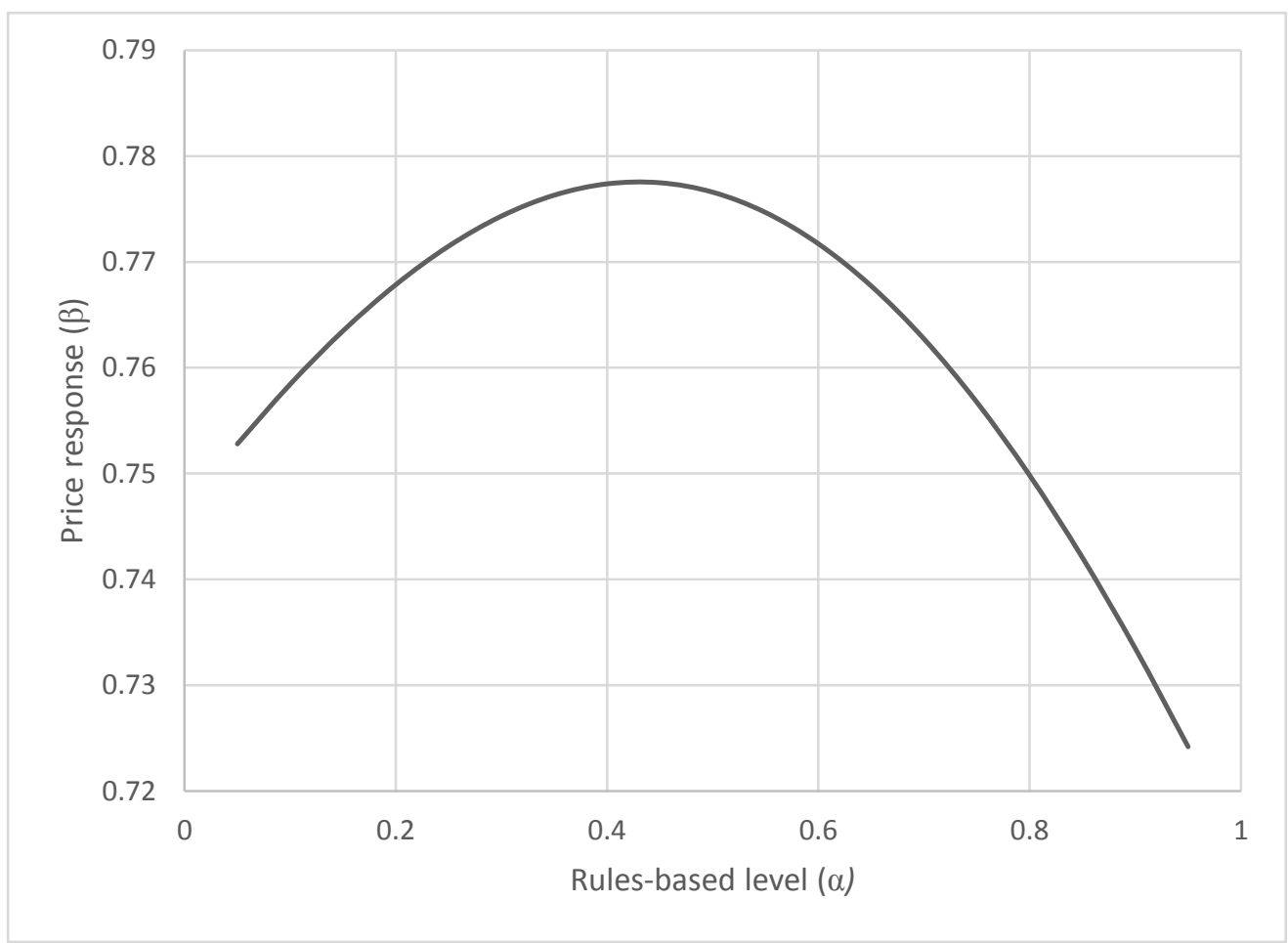

Figure 1. Price response $(\beta)$ as a function of the rules' intensity level $(\alpha)$

$$
\left(\sigma_{p}^{2}=5, \sigma_{v}^{2}=5, \sigma_{x}^{2}=1, \sigma_{y}^{2}=1, \sigma_{\delta}^{2}=5, z=0.5, \mu_{\delta}=2.05-0.15 \alpha\right)
$$

I now show, in the following proposition, that ranking standards according to $\beta$ gives identical results to ranking them according to price efficiency, defined as the inverse of the stock price deviation (price minus real economic value) variance:

Proposition 2: The rules intensity level $\alpha^{*}$ that maximizes the price response coefficient $\beta$ also maximizes price efficiency $1 / \operatorname{Var}(P-v)$. In addition, the effect of a change in $\alpha$ on the value of $\beta$ has always the same sign as the effect of this change on $1 / \operatorname{Var}(P-v)$.

Proof: See the appendix.

As an illustration, Figure 2 uses the same numerical example as is Figure 1 and shows the value of $1 / \operatorname{Var}(P-v)$ as a function of $\alpha$. The slopes of the two graphs have the same sign for every $\alpha$, as predicted in Proposition 2. Therefore, the earnings response coefficient $\beta$ can be used as a proxy for price efficiency when choosing between standards. As more efficient security prices can lead to more efficient investment decisions (Fishman and Hagerty, 1989), the value of $\alpha$ that maximizes the coefficient $\beta$ is characterizing the set of standards that optimizes resource allocation in the economy. 


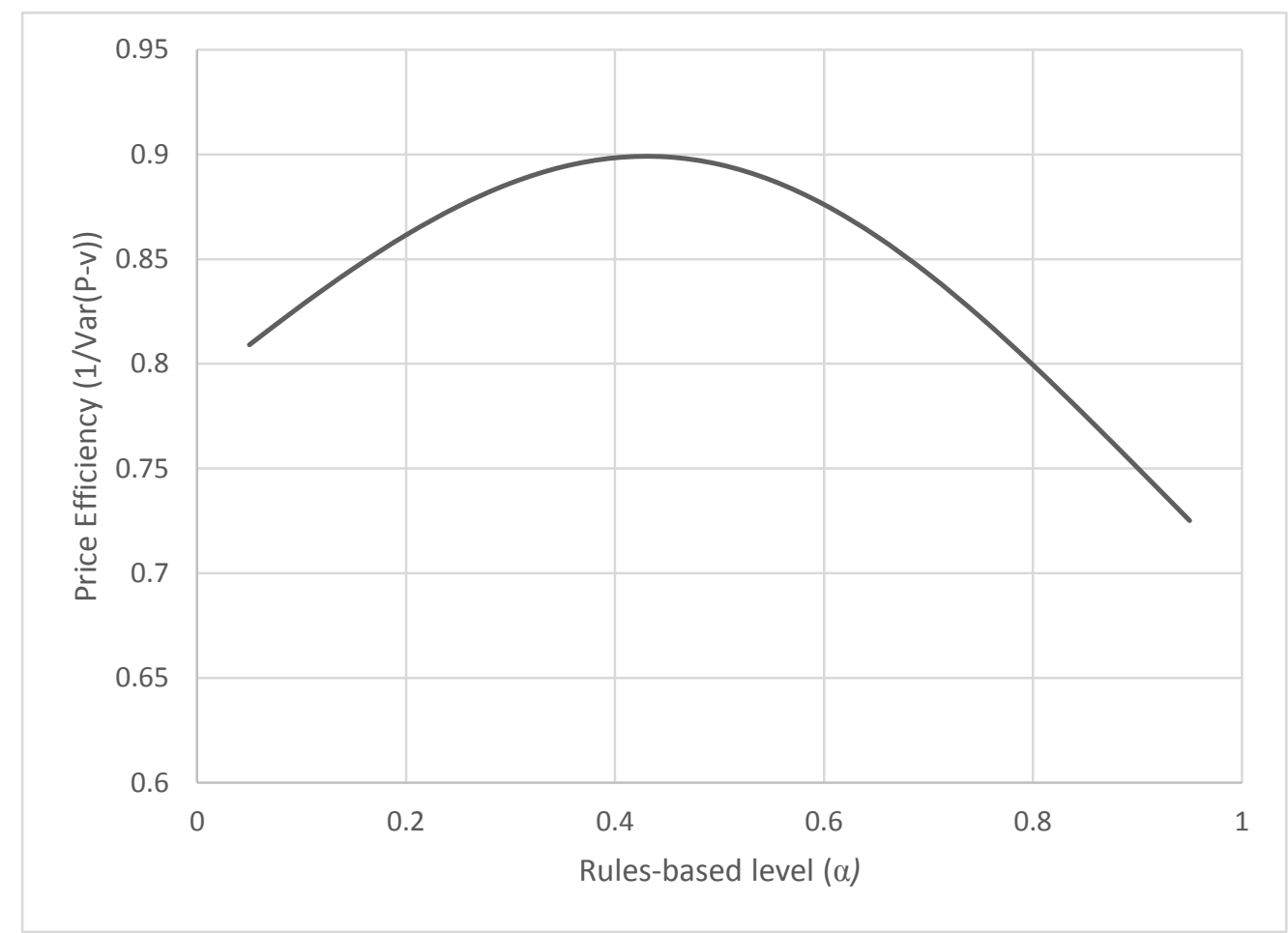

Figure 2. Price efficiency $(1 / \operatorname{Var}(P-v))$ as a function of the rules' intensity level $\alpha$

Comparative statics results for $\beta$ (which will be used in the rest of the paper as a proxy for price efficiency) are grouped in the following proposition:

Proposition 3: The price response coefficient $\beta$ is increasing in the intrinsic uncertainty of real terminal value, $\sigma_{v}^{2}$; decreasing in the inaccuracy of the rules-based system, $\sigma_{y}^{2}$; decreasing in the uncertainty of the manager's private information, $\sigma_{x}^{2}$; decreasing in managerial compensation incentives, $z$; and decreasing in the variance in the earnings management disutility across managers, $\sigma_{\delta}^{2}$.

Proof: See the appendix.

Equating the expression (22) to zero gives us the $\alpha^{*}$ level that maximizes the price efficiency $(\beta)$ :

$$
\alpha^{*}=1-\frac{\sigma_{y}^{2}}{\sigma_{y}^{2}+\beta^{2} z^{2} \sigma_{\delta}^{2}}
$$

The following proposition shows this solution is unique:

Proposition 4: There exists a unique solution for rules' intensity level $\alpha$ that maximizes the price efficiency $\beta$ for every positive value of $\sigma_{y}^{2}, \sigma_{\delta}^{2}, \sigma_{x}^{2}$, and $z$.

Proof: See the appendix.

The following proposition deals with the effects of the model's parameters on the optimal $\alpha^{*}$ :

Proposition 5: The optimal rules' intensity level $\alpha^{*}$ increases in the level of managerial compensation incentives, $z$; decreases in the inaccuracy of the rules-based system, $\sigma_{y}^{2}$; increases in the variance in the earnings management disutility across managers, $\sigma_{\delta}^{2}$; and decreases in the uncertainty of the manager's private information, $\sigma_{x}^{2}$.

Proof: See the appendix.

The first result in Proposition 5 implies that managerial compensation incentives act as a complement for accounting rules. In other words, increasing managerial compensation incentives makes the rules-based system more attractive, when the goal is price efficiency maximization. Looking at the analytical solution for $\beta$ in equation (19) can give us some intuition for this result. The incentive variable $z$ enters the formula for $\beta$ through the expression $z^{2}(1-$ $\alpha)^{2} \sigma_{\delta}^{2} \beta^{2}$ in the denominator. Therefore, $z$ affects $\beta$ by magnifying the noise due to $\sigma_{\delta}^{2}$, the variance in the earnings management disutility across managers, and it does so more for principles-based standards. Theoretically, in the extreme case where $\alpha$ equals 1 (pure rules-based), $z$ does not affect $\beta$ at all, because investors can fully back-out 
earnings management, as there is no uncertainty about the parameters that determine it. In the general case where the initial $\alpha^{*}$ is between 0 and 1 (which is the only case, according to Proposition 1), when $z$ increases, the effect of $\sigma_{\delta}^{2}$ increases and it is more difficult to back-out earnings management. Consequently, the $\alpha^{*}$ increases to optimally mitigate the problem.

Another result from Proposition 5 is that the basic trade-off between the limited ability of the accounting rules system, reflected in $\sigma_{y}^{2}$, and the uncertainty about the manager's earnings management disutility, reflected in $\sigma_{\delta}^{2}$, which affects $\beta$ (Proposition 1), also affects the optimal $\alpha^{*}$ in a predictable way.

Regarding $\sigma_{x}^{2}$, it might seem counterintuitive, at first, that when the manager knows less about his firm's value, the optimal standards should be less rules-based so that the manager's private information gets more weight in the accounting report. However, this is only one force that influences the result. An opposite force also comes into play here, dictating that the higher the volatility of $x$ relative to $y$, the easier it is to separate the effect of $x$ in the report; therefore, having the manager report more on $x$, by decreasing $\alpha$, is more desirable. The latter force is shown to be the dominant one.

An additional metric of importance is the expected earnings management. From equation (13), we know that:

$$
E(b)=z \beta \mu_{\delta}
$$

The effect of $\alpha$ on expected earnings management is possibly non-monotonic. This is a result of the non-monotonicity of $\beta$. Figure 3 shows the expected earnings management as a function of $\alpha$, compared to the $\beta$ curve assuming, for the sake of illustration, that $\mu_{\delta}{ }^{\prime}(\alpha)<0$ (If, alternatively, $\mu_{\delta}{ }^{\prime}(\alpha)>0$, then we would see the maximum point of the $\mathrm{E}(\mathrm{b})$ curve to the right of the $\beta$ curve, and not to its left as in Figure 3):

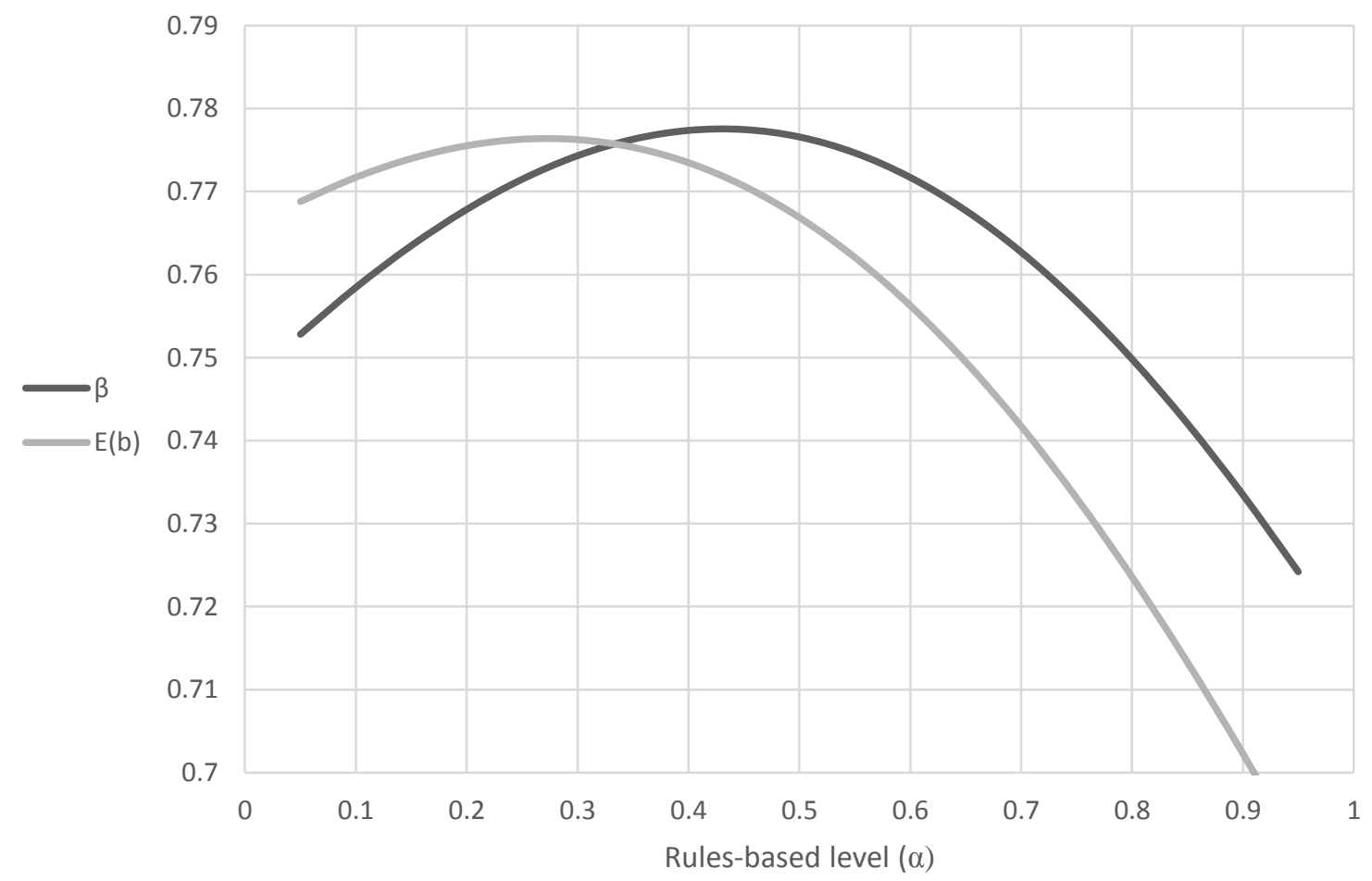

Figure 3. Expected earnings management $\mathrm{E}(\mathrm{b})$ as a function of the rules' intensity level $\alpha$ (compared to Figure 1)

In Figure 3, we can see that for a significant part of the interval both curves have the same sign to their slope, meaning that in many situations, increasing price efficiency also increases earnings management. This phenomenon introduces an economic and political trade-off between the two when determining the approach to standard-setting. On the one hand, improved price efficiency helps investors make the right choice between potential investments, improving the efficiency of resource allocation in the economy. On the other hand, the cost of earnings management to the economy (different than the subjective earnings management disutility of the manager) may include loss of 
public confidence in companies, which may bring to a decrease in the availability of future financing, and deadweight loss of litigation and regulatory enforcement.

It is reasonable to assume that standard setters and regulators have the above trade-off in mind when deciding on the optimal structure of the standards. However, if an objective function of a standard setter or regulator puts a high weight on minimizing earnings management, it may well shift the standards away from maximizing the price efficiency.

\section{Endogenizing Managerial Compensation Incentives - A Robustness Check}

In the previous section, we saw that price efficiency is non-monotonic in the standards structure, $\alpha$, and that managerial compensation incentives and accounting rules are complements. However, those results rely on an assumption of passiveness by the shareholders, meaning that managerial compensation incentives do not change when standards change. The results might change when shareholders are given the ability to affect $\beta$ by changing compensation incentives. For example, in the previous section, $\beta$ increased when the use of rules was reduced (in high levels of $\alpha$ ). However, when shareholders can change managerial compensation incentives after standards are set, it might be that they would set $z$ so that $\beta$ will decrease, to reduce the incentives for earnings management. In this section, as a robustness check for the results in the previous section, the managerial compensation incentives parameter $z$ is endogenized as a decision parameter of the shareholders.

Assume that after standards are set (level of $\alpha$ ), shareholders set the level of $z$. Assume the level of $z$ is observable by the market. The manager can affect the firm's value by changing his level of managerial effort. Knowing $z$, the manager then selects an effort level $e$ (knowing only his type $\delta$ ). The level of effort is unobservable to the market and the shareholders. I assume the manager is effort averse. The cost function of providing effort is increasing and convex and is assumed to be $0.5 \cdot e^{2}$. Effort affects the terminal value $v$ such that $\mu_{v}=e$. I assume that $\sigma_{v}^{2}$ is not affected by the choice of $e$. After the effort level is selected, the realization of the signals $x$ and $y$ are determined, after which the manager chooses the level of earnings management $b$. Therefore, the manager's problem comes in two stages. Using backward induction and focusing first on the second stage, after $e$ is chosen, and $x$ and $y$ are determined, then the manager's problem is:

$$
b(x, y, \delta)=\operatorname{argmax}_{b} z P(r=y(x, \alpha)+b)-\frac{1}{\delta} \cdot \frac{b^{2}}{2}-\frac{1}{2} e^{2}
$$

Solving the first order conditions for $b$ gives us the same solution found in equation (13):

$$
b(x, y, \delta)=z \beta \delta
$$

Going backwards to the first stage, the manager maximizes expected compensation incentives, net of effort and earnings management disutility, by choosing an effort level, knowing only the parameter $z$ and his type $\delta$, but without knowing the accounting signals $x$ and $y$. Assuming, for the simplicity of analysis, that the manager is risk neutral. The manager's problem is then:

$$
\underset{e}{\operatorname{Max}}\left\{z E[P(r=y(x, \alpha)+b)]-\frac{1}{\delta} \cdot \frac{E\left[b^{2}\right]}{2}-\frac{1}{2} e^{2}\right\}
$$

Since the expectations of $x$ and $y$ are both equal to $e$, and the optimal $b$ is not a function of $e$, then the first order condition gives us the solution for $e$ :

$$
e=z \beta
$$

It is already interesting to see, at this point, that earnings management and managerial effort are both positively related to $\beta$ and compensation incentives. This means that an increase in managerial effort caused by a change in accounting standards should result in more earnings management.

The above solution for $b$ and $e$ gives us the following solution for the firm's price (given $z$ ):

$$
P=E[v \mid r, z]=z \beta+\left[r-z \beta \mu_{\delta}-z \beta\right] \cdot \frac{\sigma_{v}^{2}}{\sigma_{v}^{2}+\sigma_{x}^{2}+\alpha^{2} \sigma_{y}^{2}+z^{2} \beta^{2}(1-\alpha)^{2} \sigma_{\delta}^{2}}
$$

and therefore, the solution for $\beta$ is the same as in equations (19) and (20), and the solution for the intercept term $\gamma$ is:

$$
\gamma=z \beta\left\{1-\beta-\mu_{\delta} \beta\right\}
$$

The shareholders would want to choose the optimal $z$, given the standards structure $\alpha$. I assume that the shareholders' goal is to maximize the firm's terminal value net of the compensation incentives given to the manager (see Baiman and Verrecchia, 1995, for a similar assumption). Therefore, the shareholders' problem is:

$$
\underset{z}{\operatorname{Max}} E[v-z p]=\operatorname{Max}_{z}[e-z e]=\operatorname{Max}_{z}[(1-z) z \beta]
$$


From the implicit function for $\beta$ in equation (20), it is known that $\beta$ is a function of $z$, and so the first order condition for $z$ should take that into account:

$$
(1-2 z) \beta+\left(z-z^{2}\right) \partial \beta / \partial z=0
$$

By differentiating the implicit equation (20), we derive (the partial derivative of $\beta$ with respect to $z$ (note that at the stage when shareholders choose $z$, the standards are given):

$$
\partial \beta / \partial z=-\frac{2 \beta^{3} z(1-\alpha)^{2} \sigma_{\delta}^{2}}{3 \beta^{2} z^{2}(1-\alpha)^{2} \sigma_{\delta}^{2}+\sigma_{v}^{2}+\sigma_{x}^{2}+\alpha^{2} \sigma_{y}^{2}}<0
$$

Placing the derivative in (32) into equation (31) gives us:

$$
(1-2 z) \beta\left[3 \beta^{2} z^{2}(1-\alpha)^{2} \sigma_{\delta}^{2}+\sigma_{v}^{2}+\sigma_{x}^{2}+\alpha^{2} \sigma_{y}^{2}\right]-2\left(z-z^{2}\right) \beta^{3} z(1-\alpha)^{2} \sigma_{\delta}^{2}=0
$$

Equations (33) and (20) form a set of implicit equations for $\beta$ and $z$. Although these equations deal with third order polynomials, it is now possible to show that:

Proposition 6: There is a unique solution $\{z, \beta\}$ for each given set of the exogenous parameters.

Proof: See the appendix.

I also assert that in this expanded model, the results of proposition 2 ( $\beta$ being a proxy for price efficiency) hold:

Proposition 7: The results of proposition 2 hold when $z$ is endogenous (as modeled in this section).

Proof: See the appendix.

A numerical solution, using specific parameter values, for the set of implicit equations can assist us in finding directional intuition for the results. Figure 4 shows $\beta$ as a function of $\alpha$. We can see that $\beta$ is still non-monotonic in $\alpha$ as in the exogenous compensation incentives case.

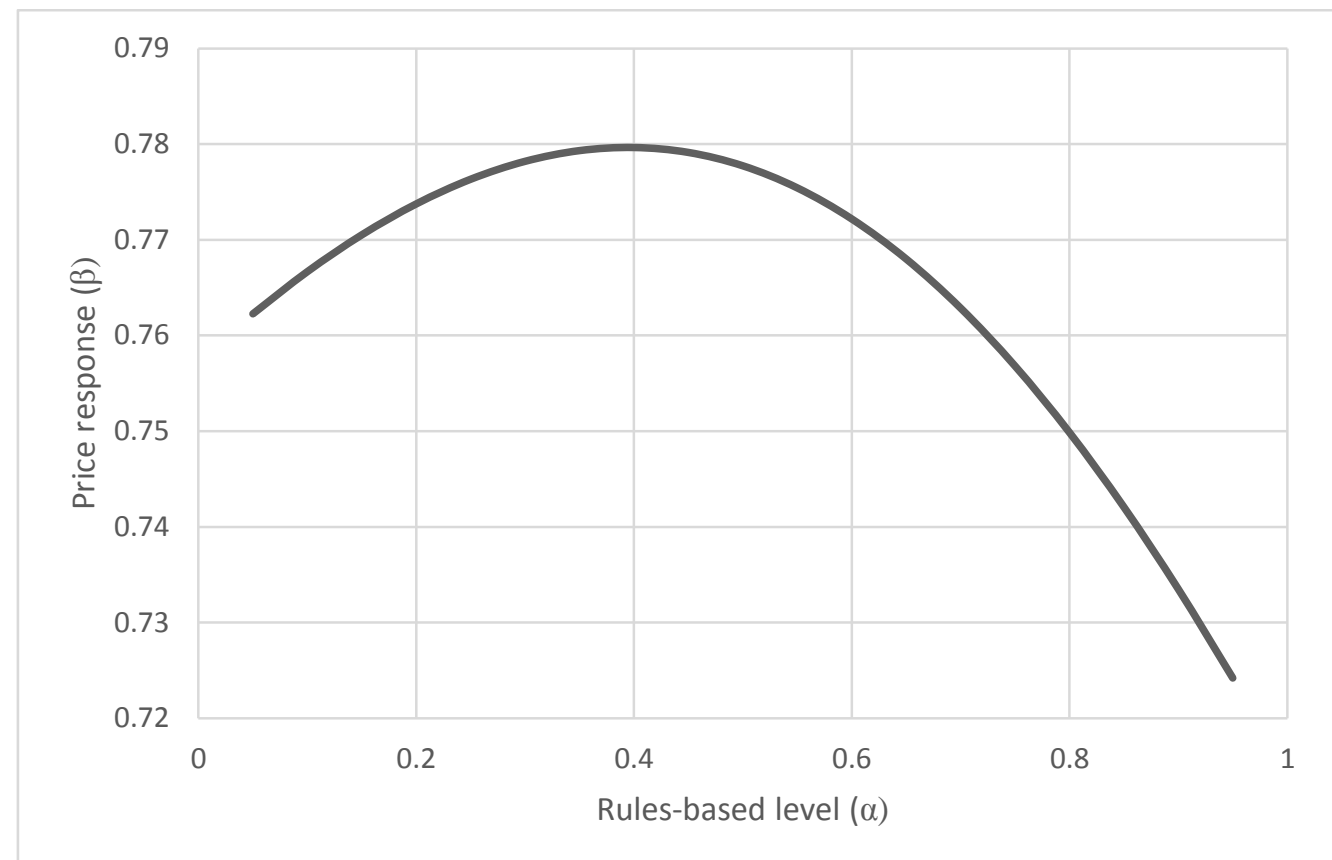

Figure 4. Price response coefficient $\beta$ as a function of the rules' intensity level $\alpha$ when managers' compensation incentives $\mathrm{z}$ is endogenous

$$
\left(\sigma_{\delta}^{2}=5, \sigma_{v}^{2}=5, \sigma_{x}^{2}=1, \sigma_{y}^{2}=1, \mu_{\delta}=2.05-0.15 \alpha\right)
$$

Figure 5 shows the optimal $z$ selected by the shareholders, as a function of $\alpha$. In this figure $z$ is monotonically increasing in $\alpha$, meaning that a more rules-based standards system requires a higher level of managerial compensation incentives for net value (terminal value minus compensation incentives) to be maximized. For intuition, we look first at equation (27) that calculates effort in equilibrium as $z \beta$. When shareholders consider a marginal increase in $z$ they know that this has the potential to increase effort, yet $\beta$ decreases due to increased noise (as I have explained in Section 4). However, the higher $\alpha$ is, the less effect $z$ has on $\beta$, and so shareholders find it 
optimal to increase $z$. This is like the result in Proposition 5, showing that managerial compensation incentives are a complement for accounting rules (however, the causality is opposite. In proposition 5, a higher $z$ requires a higher $\alpha$ for value relevance to be maximized, while in this section, a higher $\alpha$ requires a higher $z$ for net value to be maximized):

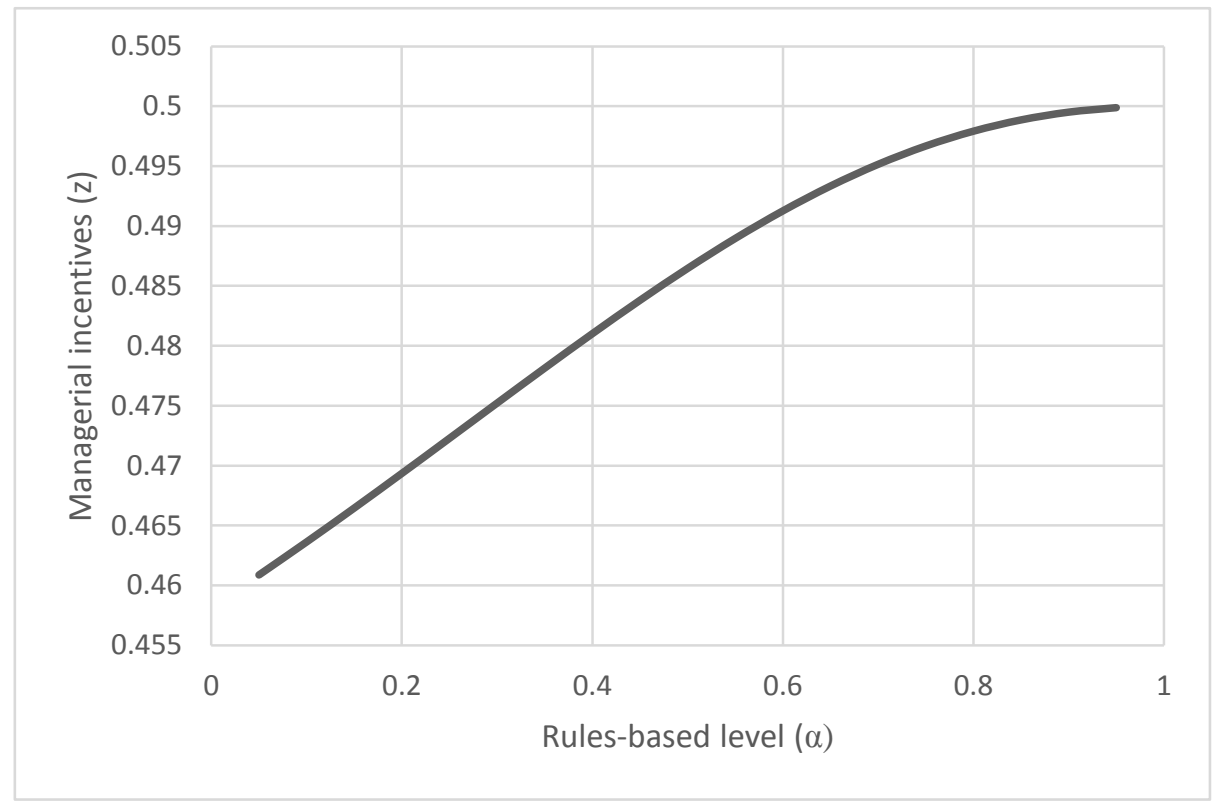

Figure 5. Managerial compensation incentives $\mathrm{z}$ as a function of the rules' intensity level $\alpha$

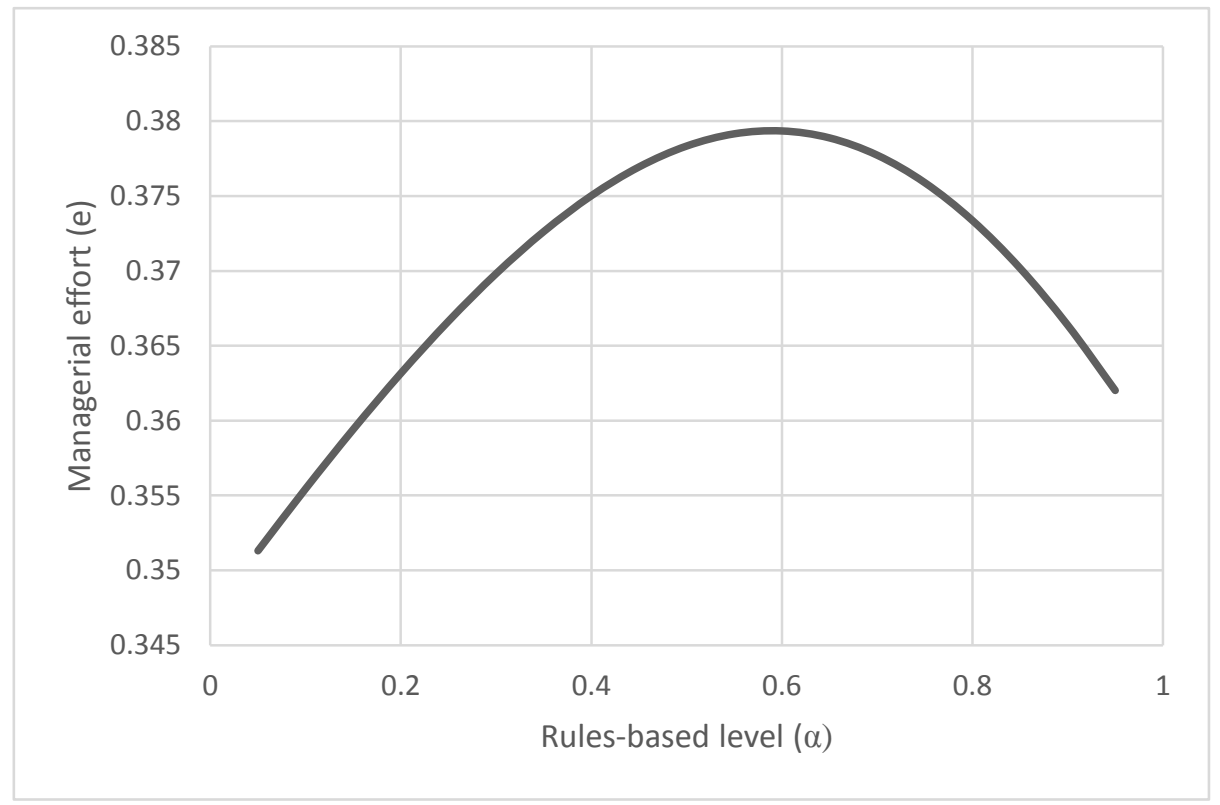

Figure 6. Managerial effort e as a function of the rules' intensity level $\alpha$

Figure 6 shows the optimal managerial effort level, $e$, as a function of $\alpha$. Managerial effort is shown to be non-monotonic, first increasing and then decreasing. This is an effect of the non-monotonicity of $\beta$. However, the value of $\alpha$ that maximizes effort is always higher than the value of $\alpha$ that maximizes price efficiency (proof: maximizing e in equation (27) gives us the first order condition: $\frac{\partial \beta}{\partial \alpha} z=-\frac{\partial z}{\partial \alpha} \beta$. Since $\frac{\partial z}{\partial \alpha}$ is always positive according to Figure 5, then the solution for maximum effort is when $\frac{\partial \beta}{\partial \alpha}<0$, meaning that it is in the decreasing part of Figure 4, and so the value of $\alpha$ that maximizes effort is higher than the value of $\alpha$ that maximizes price 
efficiency). This can provide an additional explanation for why a country would choose to adopt standards that are more rules-based than needed to maximize price efficiency.

It is also interesting to see that there is a significant region of values for $\alpha$, for which making standards less rules-based increases managerial effort while decreasing managerial compensation incentives. This means that a market that has a high initial $\alpha$ (highly rules-based) can gain increased productivity, increased price efficiency, and increased net value for shareholders by moving towards a more principles-based system.

Looking at the effect of $\alpha$ on expected earnings management, we can see in Figure 7 that it stays non-monotonic as in the previous section.

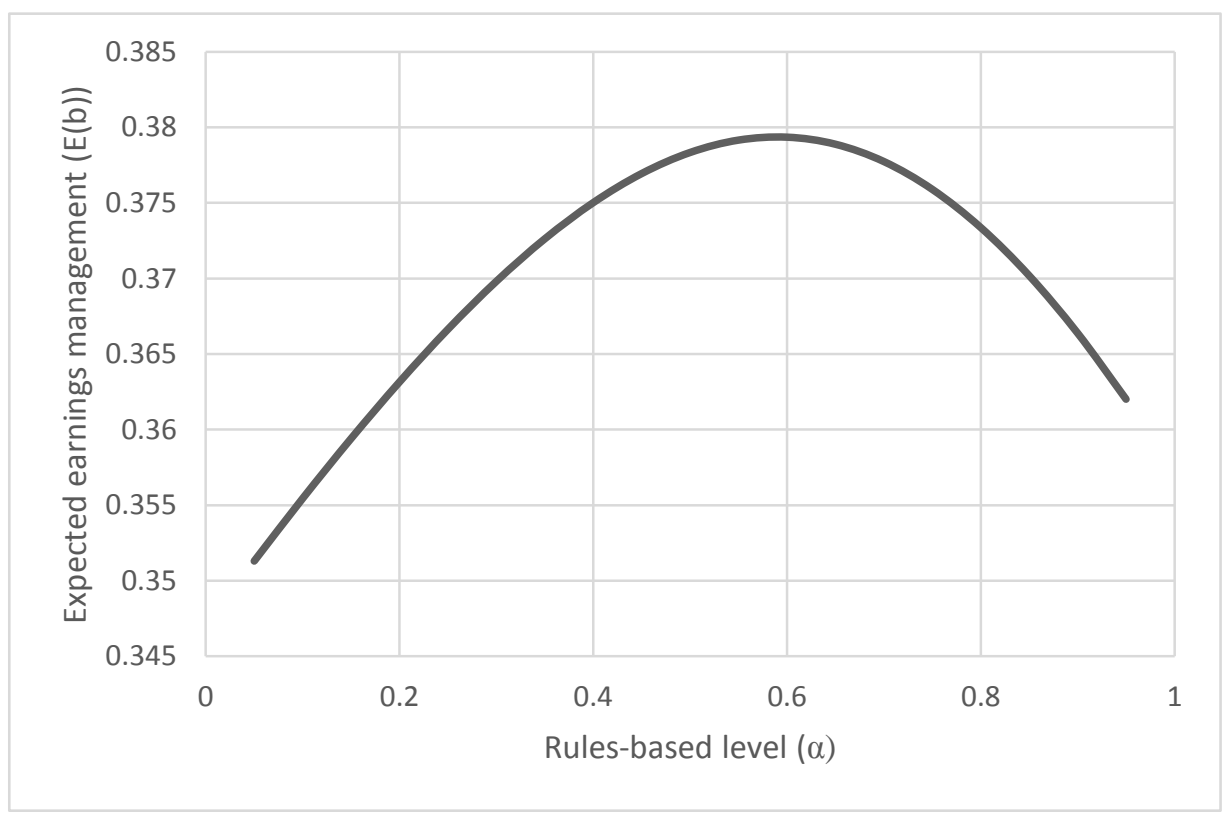

Figure 7. Expected earnings management $\mathrm{E}(\mathrm{b})$ as a function of the rules' intensity level $\alpha$ when managerial incentives are endogenous

\section{Conclusion}

This paper studies the effects of a move towards principles-based accounting standards on price efficiency in the equity market. Price efficiency is shown to be non-monotonic with respect to the use of rules incorporated in accounting standards. When standards are highly rules-based, price efficiency is enhanced when the use of rules is reduced; however, this relation reverses when standards become sufficiently principles-based. Expected earnings management is also shown to be non-monotonic in the same manner. I also show that more reliance on rules-based standards requires more managerial compensation incentives for price efficiency to be maximized.

As to empirical research applications, the model's prediction of non-monotonicity of price efficiency with respect to the use of rules-based standards means that an empirical study comparing price efficiency in regimes with different usage of rules-based standards will have to go beyond a simple linear regression analysis. In addition, the predicted monotonic positive relation between the rules' intensity level and managerial compensation incentives (Figure 5,) may also be of interest for researchers and capital market participants and can be tested using data on executive compensation in different countries.

\section{References}

Agoglia, C. P., Doupnik, T. S., \& Tsakumis G. T. (2011). Principles-Based versus Rules-Based Accounting Standards: The Influence of Standard Precision and Audit Committee Strength on Financial Reporting Decisions. The Accounting Review, 86(3), 747-767. https://doi.org/10.2308/accr.00000045

Baiman, S., \& Verrecchia, R. E. (1995). Earnings and Price-Based Compensation Contracts in the Presence of Discretionary Trading and Incomplete Contracting. Journal of Accounting and Economics, 20, 93-121. https://doi.org/10.1016/0165-4101(94)00377-H 
Barth, M. E., Beaver, W. H., \& Landsman, W. R. (2001). The Relevance of the Value-Relevance Literature for Financial Accounting Standard Setting: Another View. Journal of Accounting and Economics, 31, 77-104. https://doi.org/10.1016/S0165-4101(01)00019-2

Beck, A. K., Behn, B. K., Lionzo, A., \& Rossignoli, F. (2017). Firm Equity Investment Decisions and U.S. GAAP and IFRS Consolidation Control Guidelines: An Empirical Analysis. Journal of International Accounting Research, 16(1), 37-57. https://doi.org/10.2308/jiar-51657

Boone, J. P., Linthicum, C. L., \& Poe, A. (2013). Characteristics of Accounting Standards and SEC Review Comments. Accounting Horizons, 27(4), 711-736. https://doi.org/10.2308/acch-50551

Collins, D. I., Pasewark, W. R., Riley, M. E. (2012). Financial Reporting Outcomes under Rules-Based and Principles-Based Accounting Standards. Accounting Horizons, 26(4), 681-705. https://doi.org/10.2308/acch-50266

Cussatt, M., Huang, L., \& Pollard, T. J. (2018). Accounting Quality under U.S. GAAP versus IFRS: The Case of Germany. Journal of International Accounting Research, 17(3), 21-41. https://doi.org/10.2308/jiar-51997

Donelson, D. C., McInnis, J. M., and Mergenthaler, R. D. (2012). Rules-Based Accounting Standards and Litigation. The Accounting Review, 87(4), 1247-1279. https://doi.org/10.2308/accr-10274

Fishman, M. J., \& Hagerty, K. M. (1989). Disclosure Decisions by Firms and the Competition for Price Efficiency. The Journal of Finance, 44(3), 633-46. https://doi.org/10.1111/j.1540-6261.1989.tb04382.x

Gimbar, C., Hansen, B., \& Ozlanski, M. E. (2016). The Effects of Critical Audit Matter Paragraphs and Accounting Standard Precision on Auditor Liability. The Accounting Review, 91(6), 1629-1646. https://doi.org/10.2308/accr-51382

Guo, Z., and Luo, Y. (2017). Credit Constraint Exports in Countries with Different Degrees of Contract Enforcement. Business and Economic Research, 7(1), 227-241. https://doi.org/10.5296/ber.v7i1.10923

Jamal, K., \& Tan, H. (2010). Joint Effects of Principles-Based versus Rules-Based Standards and Auditor Type in Constraining Financial Managers' Aggressive Reporting. The Accounting Review, 85(4), 1325-1346. https://doi.org/10.2308/accr.2010.85.4.1325

Kadous, K., \& Mercer, M. (2012). Can Reporting Norms Create a Safe Harbor? Jury Verdicts against Auditors under Precise and Imprecise Accounting Standards. The Accounting Review, 87(2), 565-587.https://doi.org/10.2308/accr-10203

Kadous, K., \& Mercer, M. (2016). Are Juries More Likely to Second-Guess Auditors under Imprecise Accounting Standards? Auditing: A Journal of Practice \& Theory, 35(1), 101-117. https://doi.org/10.2308/ajpt-51016

Nelson, M. W. (2003). Behavioral Evidence on the Effects of Principles- and Rules-Based Standards. Accounting Horizons, 17(1), 91-104. https://doi.org/10.2308/acch.2003.17.1.91

Peytcheva, M., Wright, A. M. \& Majoor, B. (2014). The Impact of Principles-Based versus Rules-Based Accounting Standards on Auditors' Motivations and Evidence Demands. Behavioral Research in Accounting, 26(2), 51-72. https://doi.org/10.2308/bria-50707

Schipper, K. (2003). Commentary: Principles-Based Accounting Standards. Accounting Horizons, 17(1), 61-72.

Sun, J., Cahan, S. F., \& Emanuel, D. (2011). How Would the Mandatory Adoption of IFRS Affect the Earnings Quality of U.S. Firms? Evidence from Cross-Listed Firms in the U.S. Accounting Horizons, 25(4), 837-860. https://doi.org/10.2308/acch-50049

U.S. Securities and Exchange Commission. (2012). Work Plan for the Consideration of Incorporating International Financial Reporting Standards into the Financial Reporting System for U.S. Issuers Final Staff Report. [Online] https://www.sec.gov/spotlight/globalaccountingstandards/ifrs-work-plan-final-report.pdf 


\section{Proof of Proposition 2:}

\section{Appendix}

Using equations (1), (4), (11), (13), and (18), we get that:

$$
\begin{gathered}
P=\beta r+\gamma=\beta(y+b)+(1-\beta) \mu_{v}-z \beta^{2} \mu_{\delta}=\beta\left[v+\varepsilon_{x}+(y-x)\right]+\beta^{2} z \delta+(1-\beta) \mu_{v}-z \beta^{2} \mu_{\delta} \Rightarrow P-v \\
=\beta \varepsilon_{x}+\beta(y-x)+\beta^{2} z\left(\delta-\mu_{\delta}\right)+(1-\beta)\left(v-\mu_{v}\right)
\end{gathered}
$$

Assuming independence of the distributions of $\varepsilon_{x},(y-x), \delta$ and $v$, and using the fact that $E(P-v)=0$ because of the rational-expectations assumption, we get that:

$$
\operatorname{Var}(P-v)=\beta^{2} \sigma_{x}^{2}+\beta^{2} \alpha^{2} \sigma_{y}^{2}+\beta^{4} z^{2}(1-\alpha)^{2} \sigma_{\delta}^{2}+(1-\beta)^{2} \sigma_{v}^{2}
$$

Finding the effect of standards on this variance, the derivative is calculated:

$$
\frac{\partial \operatorname{Var}(P-v)}{\partial \alpha}=\frac{\partial \beta}{\partial \alpha}\left[2 \beta \sigma_{x}^{2}+2 \beta \alpha^{2} \sigma_{y}^{2}+4 \beta^{3} z^{2}(1-\alpha)^{2} \sigma_{\delta}^{2}-2(1-\beta) \sigma_{v}^{2}\right]+2 \beta^{2}\left[\alpha \sigma_{y}^{2}-\beta^{2} z^{2}(1-\alpha) \sigma_{\delta}^{2}\right]
$$

Using equation (21), we get:

$$
\begin{aligned}
\frac{\partial \operatorname{Var}(P-v)}{\partial \alpha}=\frac{\partial \beta}{\partial \alpha}\left[2 \beta \sigma_{x}^{2}+2 \beta \alpha^{2} \sigma_{y}^{2}+4 \beta^{3} z^{2}(1-\alpha)^{2} \sigma_{\delta}^{2}-2(1-\beta) \sigma_{v}^{2}\right]-\frac{\partial \beta}{\partial \alpha} \beta\left[3 \beta^{2} z^{2}(1-\alpha)^{2} \sigma_{\delta}^{2}+\sigma_{v}^{2}+\sigma_{x}^{2}\right. \\
\left.+\alpha^{2} \sigma_{y}^{2}\right]
\end{aligned}
$$

Using equation (20) twice (in both square brackets), we get that:

$$
\frac{\partial \operatorname{Var}(P-v)}{\partial \alpha}=\frac{\partial \beta}{\partial \alpha} 2 \beta^{3} z^{2}(1-\alpha)^{2} \sigma_{\delta}^{2}-\frac{\partial \beta}{\partial \alpha} \beta\left[2 \beta^{2} z^{2}(1-\alpha)^{2} \sigma_{\delta}^{2}+\sigma_{v}^{2}\right]=-\frac{\partial \beta}{\partial \alpha} \sigma_{v}^{2}
$$

Which means that $\frac{\partial \operatorname{Var}(P-v)}{\partial \alpha}$ always has an opposite sign than $\frac{\partial \beta}{\partial \alpha}$.

\section{Proof of Proposition 3:}

About the intrinsic uncertainty of real terminal value:

$$
\frac{\partial \beta}{\partial \sigma_{v}^{2}}=\frac{1-\beta}{3 \beta^{2} z^{2}(1-\alpha)^{2} \sigma_{\delta}^{2}+\sigma_{v}^{2}+\sigma_{x}^{2}+\alpha^{2} \sigma_{y}^{2}}>0
$$

as it was shown that $0<\beta<1$.

About the inaccuracy of the rules-based system:

$$
\frac{\partial \beta}{\partial \sigma_{y}^{2}}=\frac{-\alpha^{2} \beta}{3 \beta^{2} z^{2}(1-\alpha)^{2} \sigma_{\delta}^{2}+\sigma_{v}^{2}+\sigma_{x}^{2}+\alpha^{2} \sigma_{y}^{2}}<0
$$

With regard to the uncertainty in managerial private information:

$$
\frac{\partial \beta}{\partial \sigma_{x}^{2}}=\frac{-\beta}{3 \beta^{2} z^{2}(1-\alpha)^{2} \sigma_{\delta}^{2}+\sigma_{v}^{2}+\sigma_{x}^{2}+\alpha^{2} \sigma_{y}^{2}}<0
$$

About managerial compensation incentives $z$ :

$$
\frac{\partial \beta}{\partial z}=\frac{-2 \beta^{3} z(1-\alpha)^{2} \sigma_{\delta}^{2}}{3 \beta^{2} z^{2}(1-\alpha)^{2} \sigma_{\delta}^{2}+\sigma_{v}^{2}+\sigma_{x}^{2}+\alpha^{2} \sigma_{y}^{2}}<0
$$

And about the variance of the earnings management disutility:

\section{Proof of Proposition 4:}

$$
\frac{\partial \beta}{\partial \sigma_{p}^{2}}=\frac{-\beta^{3} z^{2}(1-\alpha)^{2}}{3 \beta^{2} z^{2}(1-\alpha)^{2} \sigma_{\delta}^{2}+\sigma_{v}^{2}+\sigma_{x}^{2}+\alpha^{2} \sigma_{y}^{2}}<0
$$

We saw that:

$$
\frac{\partial \beta}{\partial \alpha}=\frac{2 \beta\left[(1-\alpha) \beta^{2} z^{2} \sigma_{\delta}^{2}-\alpha \sigma_{y}^{2}\right]}{3 \beta^{2} z^{2}(1-\alpha)^{2} \sigma_{\delta}^{2}+\sigma_{v}^{2}+\sigma_{x}^{2}+\alpha^{2} \sigma_{y}^{2}}
$$

The sign of this derivative is determined by the expression in the square brackets:

$$
\mathrm{M}=(1-\alpha) \beta^{2} z^{2} \sigma_{\delta}^{2}-\alpha \sigma_{y}^{2}
$$

$\mathrm{M}$ is positive when $\alpha=0$ and negative when $\alpha=1$, and so there is a point in between 0 and 1 in which $\mathrm{M}$ equals 0 . We can now take the derivative of $\mathrm{M}$ with respect to $\alpha$ : 


$$
\frac{\partial M}{\partial \alpha}=-\sigma_{y}^{2}-\beta^{2} z^{2} \sigma_{\delta}^{2}+2(1-\alpha) \beta z^{2} \sigma_{\delta}^{2} \cdot \frac{\partial \beta}{\partial \alpha}
$$

When $\alpha$ is 1 (or close enough to 1 ) both $M$ and $\frac{\partial \beta}{\partial \alpha}$ are negative, and $\frac{\partial M}{\partial \alpha}$ is negative. As we decrease $\alpha$, the expression $\mathrm{M}$ increases until we get a solution for $\alpha *$ at $\alpha *=\alpha_{0}$. We know that at $\alpha *=\alpha_{0}$, the derivative $\frac{\partial \beta}{\partial \alpha}$ is zero, and so $\frac{\partial M}{\partial \alpha}$ is negative. In order to have another solution for $\alpha *$, such that $\alpha *<\alpha_{0}$, we need the expression M to start decreasing when we decrease $\alpha$ further, until it reaches 0 again. This means that in the second solution (the closest to $\alpha_{0}$ ), the derivative $\frac{\partial M}{\partial \alpha}$ should be non-negative. However, we know that when $\mathrm{M}=0$, then $\frac{\partial \beta}{\partial \alpha}$ equals 0 and so $\frac{\partial M}{\partial \alpha}$ is negative. This contradiction proves that there is no other solution other than the first unique solution. The existence of a solution has been shown in Proposition 1.

\section{Proof of Proposition 5:}

1) With regard to the effect of $z$ :

$$
\frac{\partial \alpha *}{\partial z}=\frac{\sigma_{y}^{2}}{\left(\sigma_{y}^{2}+\beta^{2} z^{2} \sigma_{\delta}^{2}\right)^{2}} 2 \beta z \sigma_{\delta}^{2}\left(\beta+z \frac{\partial \beta}{\partial z}\right)
$$

We know that:

$$
\frac{\partial \beta}{\partial z}=\frac{-2 \beta^{3} z(1-\alpha)^{2} \sigma_{\delta}^{2}}{3 \beta^{2} z^{2}(1-\alpha)^{2} \sigma_{\delta}^{2}+\sigma_{v}^{2}+\sigma_{x}^{2}+\alpha^{2} \sigma_{y}^{2}}<0
$$

Placing the latter derivative in the first one, we get:

$$
\frac{\partial \alpha *}{\partial z}=\frac{\sigma_{y}^{2}}{\left(\sigma_{y}^{2}+\beta^{2} z^{2} \sigma_{\delta}^{2}\right)^{2}} 2 \beta z \sigma_{\delta}^{2}\left(\beta-\frac{2 \beta^{3} z^{2}(1-\alpha)^{2} \sigma_{\delta}^{2}}{3 \beta^{2} z^{2}(1-\alpha)^{2} \sigma_{\delta}^{2}+\sigma_{v}^{2}+\sigma_{x}^{2}+\alpha^{2} \sigma_{y}^{2}}\right)
$$

We can see that:

$$
L=\frac{2 \beta^{3} z^{2}(1-\alpha)^{2} \sigma_{\delta}^{2}}{3 \beta^{2} z^{2}(1-\alpha)^{2} \sigma_{\delta}^{2}+\sigma_{v}^{2}+\sigma_{\chi}^{2}+\alpha^{2} \sigma_{y}^{2}}<\frac{2 \beta^{3} z^{2}(1-\alpha)^{2} \sigma_{\delta}^{2}}{3 \beta^{2} z^{2}(1-\alpha)^{2} \sigma_{\delta}^{2}}=\frac{2}{3} \beta
$$

Placing $\mathrm{L}$ in the derivative, we get:

$$
\frac{\partial \alpha *}{\partial z}=\frac{\sigma_{y}^{2}}{\left(\sigma_{y}^{2}+\beta^{2} z^{2} \sigma_{\delta}^{2}\right)^{2}} 2 \beta z \sigma_{\delta}^{2}(\beta-L)>\frac{\sigma_{y}^{2}}{\left(\sigma_{y}^{2}+\beta^{2} z^{2} \sigma_{\delta}^{2}\right)^{2}} \frac{2}{3} \beta^{2} z \sigma_{\delta}^{2}>0
$$

2) With regard to the effect of the inaccuracy of the rules-based system, $\sigma_{y}^{2}$ :

$$
\frac{\partial \alpha *}{\partial \sigma_{y}^{2}}=\frac{-\sigma_{y}^{2}-\beta^{2} z^{2} \sigma_{\delta}^{2}+\sigma_{y}^{2}\left(1+2 \beta z^{2} \sigma_{\delta}^{2} \frac{\partial \beta}{\partial \sigma_{y}^{2}}\right)}{\left(\sigma_{y}^{2}+\beta^{2} z^{2} \sigma_{\delta}^{2}\right)^{2}}=\frac{-\beta^{2} z^{2} \sigma_{\delta}^{2}+2 \beta z^{2} \sigma_{\delta}^{2} \sigma_{y}^{2} \frac{\partial \beta}{\partial \sigma_{y}^{2}}}{\left(\sigma_{y}^{2}+\beta^{2} z^{2} \sigma_{\delta}^{2}\right)^{2}}
$$

In Proposition 3, it was shown that $\frac{\partial \beta}{\partial \sigma_{y}^{2}}<0$, and so $\frac{\partial \alpha *}{\partial \sigma_{y}^{2}}<0$.

About the variance in the earnings management disutility, $\sigma_{\delta}^{2}$ :

$$
\frac{\partial \alpha *}{\partial \sigma_{\delta}^{2}}=\frac{\sigma_{y}^{2}\left(\beta^{2} z^{2}+2 \beta z^{2} \sigma_{\delta}^{2} \frac{\partial \beta}{\partial \sigma_{\delta}^{2}}\right)}{\left(\sigma_{y}^{2}+\beta^{2} z^{2} \sigma_{\delta}^{2}\right)^{2}}
$$

We know that:

$$
\frac{\partial \beta}{\partial \sigma_{\delta}^{2}}=\frac{-\beta^{3} z^{2}(1-\alpha)^{2}}{3 \beta^{2} z^{2}(1-\alpha)^{2} \sigma_{\delta}^{2}+\sigma_{v}^{2}+\sigma_{x}^{2}+\alpha^{2} \sigma_{y}^{2}}
$$

Placing the latter derivative in the first one, we get:

$$
\frac{\partial \alpha *}{\partial \sigma_{\delta}^{2}}=\frac{\sigma_{y}^{2}}{\left(\sigma_{y}^{2}+\beta^{2} z^{2} \sigma_{\delta}^{2}\right)^{2}}\left(\beta^{2} z^{2}-\frac{2 \beta^{4} z^{4}(1-\alpha)^{2} \sigma_{\delta}^{2}}{3 \beta^{2} z^{2}(1-\alpha)^{2} \sigma_{\delta}^{2}+\sigma_{v}^{2}+\sigma_{x}^{2}+\alpha^{2} \sigma_{y}^{2}}\right)
$$

We can see that:

$$
N=\frac{2 \beta^{4} z^{4}(1-\alpha)^{2} \sigma_{\delta}^{2}}{3 \beta^{2} z^{2}(1-\alpha)^{2} \sigma_{\delta}^{2}+\sigma_{v}^{2}+\sigma_{x}^{2}+\alpha^{2} \sigma_{y}^{2}}<\frac{2 \beta^{4} z^{4}(1-\alpha)^{2} \sigma_{\delta}^{2}}{3 \beta^{2} z^{2}(1-\alpha)^{2} \sigma_{\delta}^{2}}=\frac{2}{3} \beta^{2} z^{2}
$$


Placing $\mathrm{N}$ in the derivative, we get:

$$
\frac{\partial \alpha *}{\partial \sigma_{\delta}^{2}}=\frac{\sigma_{y}^{2}}{\left(\sigma_{y}^{2}+\beta^{2} z^{2} \sigma_{\delta}^{2}\right)^{2}}\left(\beta^{2} z^{2}-N\right)>\frac{\sigma_{y}^{2}}{\left(\sigma_{y}^{2}+\beta^{2} z^{2} \sigma_{\delta}^{2}\right)^{2}} \cdot \frac{1}{3} \beta^{2} z^{2}>0
$$

3) With regard to the effect of $\sigma_{x}^{2}$ :

$$
\frac{\partial \alpha *}{\partial \sigma_{x}^{2}}=\frac{\sigma_{y}^{2}}{\left(\sigma_{y}^{2}+\beta^{2} z^{2} \sigma_{\delta}^{2}\right)^{2}} 2 \beta z^{2} \sigma_{\delta}^{2} \frac{\partial \beta}{\partial \sigma_{x}^{2}}<0
$$

Since we know from Proposition 3 that:

$$
\frac{\partial \beta}{\partial \sigma_{x}^{2}}=\frac{-\beta}{3 \beta^{2} z^{2}(1-\alpha)^{2} \sigma_{\delta}^{2}+\sigma_{v}^{2}+\sigma_{x}^{2}+\alpha^{2} \sigma_{y}^{2}}<0
$$

\section{Proof of Proposition 6:}

The first order condition for $z$ in the shareholders net value maximizing problem is (equation (33)):

$$
\begin{gathered}
(1-2 z) \beta\left[3 \beta^{2} z^{2}(1-\alpha)^{2} \sigma_{\delta}^{2}+\sigma_{v}^{2}+\sigma_{x}^{2}+\alpha^{2} \sigma_{y}^{2}\right]-2\left(z-z^{2}\right) \beta^{3} z(1-\alpha)^{2} \sigma_{\delta}^{2}=0 \\
\Rightarrow(1-2 z)\left[3 \beta^{2} z^{2}(1-\alpha)^{2} \sigma_{\delta}^{2}+\sigma_{v}^{2}+\sigma_{x}^{2}+\alpha^{2} \sigma_{y}^{2}\right]-(1-z) 2 \beta^{2} z^{2}(1-\alpha)^{2} \sigma_{\delta}^{2}=0 \\
\Rightarrow(1-4 z) \beta^{2} z^{2}(1-\alpha)^{2} \sigma_{\delta}^{2}+(1-2 z)\left[\sigma_{v}^{2}+\sigma_{x}^{2}+\alpha^{2} \sigma_{y}^{2}\right]=0
\end{gathered}
$$

We can already see from the latter simplified equation that the solution for $z$ should be between 0.25 and 0.5 because if $z<0.25$, then $(1-4 z)>0$ and $(1-2 z)>0$, and consequently the left-hand side of the equation is strictly positive, and if $\mathrm{z}>0.5$, then $(1-4 \mathrm{z})<0$ and $(1-2 \mathrm{z})<0$, and consequently the left-hand side of the equation is strictly negative.

$\mathrm{Q}$ denotes the left-hand side of the latter simplified equation. It would be shown that $\mathrm{Q}$ is monotonically decreasing in $z$ in the region $z \in[0.25,0.5]$. The derivative of $\mathrm{Q}$ with respect to $z$, considering that $\beta$ is a function of $z$, is:

$$
\begin{aligned}
& \left(2 z-12 z^{2}\right) \beta^{2}(1-\alpha)^{2} \sigma_{\delta}^{2}+2\left(z^{2}-4 z^{3}\right) \beta(1-\alpha)^{2} \sigma_{\delta}^{2} \frac{\partial \beta}{\partial z}-2\left[\sigma_{v}^{2}+\sigma_{x}^{2}+\alpha^{2} \sigma_{y}^{2}\right] \\
& (1-6 z) \cdot 2 \beta^{2} z(1-\alpha)^{2} \sigma_{\delta}^{2}+(1-4 z) \cdot 2 \beta z^{2}(1-\alpha)^{2} \sigma_{\delta}^{2} \frac{\partial \beta}{\partial z}-2\left[\sigma_{v}^{2}+\sigma_{x}^{2}+\alpha^{2} \sigma_{y}^{2}\right]
\end{aligned}
$$

Analyzing the sign of each of the components, we get that:

(1) $(1-6 z) \cdot 2 \beta^{2} z(1-\alpha)^{2} \sigma_{\delta}^{2}<0$ as $(1-6 z)<0$ when $\mathrm{z}>0.25$

(2) $(1-4 z) \cdot 2 \beta z^{2}(1-\alpha)^{2} \sigma_{\delta}^{2} \frac{\partial \beta}{\partial z}>0$ as $(1-4 z)<0$ when $z>0.25$ and $\frac{\partial \beta}{\partial z}<0$ from equation (34).

(3) $-2\left[\sigma_{v}^{2}+\sigma_{x}^{2}+\alpha^{2} \sigma_{y}^{2}\right]<0$

I show that the second component is smaller, in absolute value, than the first component, and so the entire expression is negative. First, when $0.25<z<0.5$, then it is obvious that: $|1-4 z|<|1-6 z|$. Now it is left to show that:

We know that:

$$
\left|2 \beta^{2} z(1-\alpha)^{2} \sigma_{\delta}^{2}\right|>\left|2 \beta z^{2}(1-\alpha)^{2} \sigma_{\delta}^{2} \frac{\partial \beta}{\partial z}\right| \Rightarrow|\beta|>\left|z \frac{\partial \beta}{\partial z}\right|
$$

$$
\left|z \frac{\partial \beta}{\partial z}\right|=\frac{2 \beta^{3} z^{2}(1-\alpha)^{2} \sigma_{\delta}^{2}}{3 \beta^{2} z^{2}(1-\alpha)^{2} \sigma_{\delta}^{2}+\sigma_{v}^{2}+\sigma_{x}^{2}+\alpha^{2} \sigma_{y}^{2}}<\frac{2 \beta^{3} z^{2}(1-\alpha)^{2} \sigma_{\delta}^{2}}{3 \beta^{2} z^{2}(1-\alpha)^{2} \sigma_{\delta}^{2}}=\frac{2}{3} \beta
$$

And so it is proved that the first component offsets the second one, and therefore the entire derivative is negative all through the region $[0.25,0.5]$, and so the first order condition of the net value maximizing problem has only one solution for $z$.

About $\beta$, it has already been shown in the text (Section 3) that with a given $z$, there is only one solution to $\beta$. 


\section{Proof of Proposition 7:}

In a similar way to the proof of Proposition 2, we get that:

$$
P-v=\beta \varepsilon_{x}+\beta(y-x)+\beta^{2} z\left(\delta-\mu_{\delta}\right)-(1-\beta)(v-z \beta)
$$

Assuming independence of the distributions of $\varepsilon_{x},(y-x), \delta$ and $v$, and using the fact that $\mathrm{E}(P-v)=0$ because of the rational-expectations assumption, we get that:

$$
\operatorname{Var}(P-v)=\beta^{2} \sigma_{x}^{2}+\beta^{2} \alpha^{2} \sigma_{y}^{2}+\beta^{4} z^{2}(1-\alpha)^{2} \sigma_{\delta}^{2}+(1-\beta)^{2} \sigma_{v}^{2}
$$

Finding the effect of standards on this variance, the derivative is calculated:

$$
\begin{aligned}
& \frac{\partial \operatorname{Var}(P-v)}{\partial \alpha}=\frac{\partial \beta}{\partial \alpha}\left[2 \beta \sigma_{x}^{2}+2 \beta \alpha^{2} \sigma_{y}^{2}+4 \beta^{3} z^{2}(1-\alpha)^{2} \sigma_{\delta}^{2}-2(1-\beta) \sigma_{v}^{2}\right] \\
& +\beta\left\{2 \beta\left[\alpha \sigma_{y}^{2}-\beta^{2} z^{2}(1-\alpha) \sigma_{\delta}^{2}\right]+2 \beta^{3} z(1-\alpha)^{2} \sigma_{\delta}^{2} \frac{\partial z}{\partial \alpha}\right\}
\end{aligned}
$$

Calculating $\frac{\partial \beta}{\partial \alpha}$ we get:

$$
\frac{\partial \beta}{\partial \alpha}=\frac{2 \beta\left[(1-\alpha) \beta^{2} z^{2} \sigma_{\delta}^{2}-\alpha \sigma_{y}^{2}\right]-2 \beta^{3} z(1-\alpha)^{2} \sigma_{\delta}^{2} \frac{\partial z}{\partial \alpha}}{3 \beta^{2} z^{2}(1-\alpha)^{2} \sigma_{\delta}^{2}+\sigma_{v}^{2}+\sigma_{x}^{2}+\alpha^{2} \sigma_{y}^{2}}
$$

Using the above equation, we get that:

$$
\begin{gathered}
\frac{\partial \operatorname{Var}(P-v)}{\partial \alpha}=\frac{\partial \beta}{\partial \alpha}\left[2 \beta \sigma_{x}^{2}+2 \beta \alpha^{2} \sigma_{y}^{2}+4 \beta^{3} z^{2}(1-\alpha)^{2} \sigma_{\delta}^{2}-2(1-\beta) \sigma_{v}^{2}\right]-\frac{\partial \beta}{\partial \alpha} \beta\left[3 \beta^{2} z^{2}(1-\alpha)^{2} \sigma_{\delta}^{2}+\sigma_{v}^{2}+\sigma_{x}^{2}\right. \\
\left.+\alpha^{2} \sigma_{y}^{2}\right]
\end{gathered}
$$

The rest of the proof is identical to the proof of Proposition 2. 